\title{
Co-culture with Schwann cells is an effective way for adipose-derived stem cells neural transdifferentiation
}

Dapeng Liao', Ping Gong ${ }^{2}$, Xiaojie Li', Zhen Tan², Quan Yuan ${ }^{1}$

1State Key Laboratory of Oral Diseases (Sichuan University), Chengdu, China 2Dental Implant Centre, West China College of Stomatology, Sichuan University, Chengdu, China

Submitted: 30 August 2008

Accepted: 22 November 2008

Arch Med Sci 2010; 6, 2: 145-151

DOI: 10.5114 /aoms.2010.13885

Copyright @ 2010 Termedia \& Banach

\section{Abstract}

Introduction: Adipose-derived stem cells (ADSCs) could accomplish neural transdifferentiation with the presence of certain growth factors in vitro. It has been proved that bone marrow stromal cells (BMSCs) can realize neural transdifferentiation only by being co-cultured with Schwann cells (SCs), and in our former studies we have confirmed that ADSCs could do so too. This paper aims to investigate whether the neural induction efficiency of co-culture is as high as that of other strategies using chemicals or chemicals combined with some growth factors.

Material and methods: We isolated and multiplied ADSCs from adult SpragueDawley rats, and SCs from sciatic nerves of 1-to-2-day-old Sprague-Dawley rat pups, then induced ADSCs neural transdifferentiation through $2 \%$ dimethyl sulphoxide (DMSO) and DMSO combined with growth factors. Meanwhile we co-cultured ADSCs and SCS in Transwell culture dishes without intercellular contacts. Immunostaining and RT-PCR were adopted to investigate the neural transdifferentiation of ADSCs. Then we compared the expression differences for genes S100, nestin and GFAP of the above three protocols by real-time PCR.

Results: Both immunostaining and RT-PCR proved that ADSCs could accomplish neural transdifferentiation through each of the above three protocols. And realtime PCR further shows that the gene expression relative quantities for the above three genes are not statistically different between co-culture and induction through DMSO combined with growth factors $(p>0.05)$, but both of them are statistically different from induction only by DMSO $(p<0.05)$.

Conclusions: Co-culturing ADSCs and SCs may be a simple, effective and practical way for ADSCs neural transdifferentiation.

Key words: stem cells, Schwann cells, neural transdifferentiation, co-culture.

\section{Introduction}

Schwann cells (SCS) play a pivotal role in the regeneration and development of peripheral nerves [1, 2]; however, it is not easy to acquire sufficient and highly purified SCs for clinical application without additional morbidity to the nerve donor site, so other strategies are desired.

Adipose-derived stem cells (ADSCs) are isolated from adipose tissue derived from embryonic mesoderm. They are capable of self-renewal and

\author{
Corresponding author: \\ Prof. Ping Gong \\ West China College \\ of Stomatology, \\ Sichuan University \\ No. 14, Third Section \\ Renmin Nan Road, Chengdu \\ Sichuan, 610041, China \\ Phone: +86-28-85503579 \\ Fax: +86-28-85582167 \\ E-mail: \\ dentistgong@hotmail.com
}


can differentiate along several mesenchymal tissue lineages, including adipocytes, osteoblasts, myocytes, chondrocytes, endothelial cells and cardiomyocytes $[3,4]$. Liposuction is a common and safe surgical procedure, while subcutaneous adipose tissue is abundant, readily accessible, and relatively expendable, so enough ADSCs can be obtained with minimal risk [5]. Recently it has been proved that ADSCs may also be induced into neurallike cells or a Schwann cell phenotype with the presence of some growth factors in vitro [6-8]. Last year, Zurita et al. [9] reported that bone marrow stromal cells (BMSCs) can realize neural transdifferentiation only by being co-cultured with Schwann cells (SCS) indirectly, and in our former studies we have confirmed that ADSCs could behave so too [10]. So ADSCs may be an ideal alternative cell source for SCs.

Although co-culture seems a simple and possible way to acquire sufficient SCs, we still need to know whether the neural induction efficiency of co-culture is as high as that of other strategies, such as induction by chemicals or chemicals combined with some growth factors. To investigate this problem, we adopted three protocols for neural induction of ADSCs, aiming to compare their neural induction efficiency.

\section{Material and methods}

All animal experiments described in this report were approved by the Ethical Guideline Committee for Animal Care of West China College of Medical Sciences, Sichuan University.

\section{Isolation and culture of adipose-derived stem} cells and Schwann cells

Adipose-derived stem cells were isolated from the subcutaneous adipose tissue of the inguinal region of adult Sprague-Dawley rats. The subcutaneous fat was carefully dissected and minced using sterile scissors. The cut tissue was then enzymatically dissociated for $60 \mathrm{~min}$ at $37^{\circ} \mathrm{C}$ using $0.1 \%(\mathrm{w} / \mathrm{v})$ collagenase type I (Sigma, UK). The solution was passed through a $75-\mu \mathrm{m}$ filter to remove undissociated tissue, neutralized by the addition of $\alpha$-Modified Eagle Medium ( $\alpha$-MEM; Hyclone, USA) containing $20 \%(\mathrm{v} / \mathrm{v})$ fetal bovine serum (FBS, Hyclone, USA) and centrifuged at 1000×g for $8 \mathrm{~min}$. The stromal cell pellet was resuspended in $\alpha-M E M$ containing 20\% (v/v) FBS (Hyclone, USA) with $1 \%$ $(\mathrm{v} / \mathrm{v})$ penicillin/streptomycin solution. Cultures were maintained at subconfluent levels in a $37^{\circ} \mathrm{C}$ incubator with $5 \% \mathrm{CO}_{2}$ and passaged with trypsin/EDTA (Sigma, UK) when required.

Schwann cells were first isolated from the bilateral sciatic nerves of 1-to-2-day-old SpragueDawley rat pups under aseptic conditions and placed into Hank's balanced salt solution supplemented with $1 \% \quad(v / v)$ penicillin/streptomycin. The epineurium and connective tissue were carefully removed on ice under a microscope, and the sciatic nerves were cut into $1 \mathrm{~mm}$ fragments, and then dissociated with $0.25 \%$ trypsin (Sigma, UK) and 0.1\% collagenase (Sigma, UK) for $30 \mathrm{~min}$ at $37^{\circ} \mathrm{C}$. The solution was neutralized by the addition of $\alpha$-Modified Eagle Medium ( $\alpha$-MEM; Hyclone, USA) containing $20 \%(\mathrm{v} / \mathrm{v})$ fetal bovine serum (FBS, Hyclone, USA) and centrifuged at $1000 \times \mathrm{g}$ for $8 \mathrm{~min}$. The cell pellet was resuspended in $\alpha$-MEM containing 20\% (v/v) FBS (Hyclone, USA) with 1\% (v/v) penicillin/streptomycin solution and cultured in a $37^{\circ} \mathrm{C}$ incubator with $5 \% \quad \mathrm{CO}_{2}$. After 24 h, G418 (Gibeco, Germany) was added to the culture to a final concentration of $100 \mathrm{mg} / \mathrm{l}$ for another 3 days. This was replaced with $\alpha$-MEM containing 20\% FBS, and 3 days later the G418 treatment was repeated. Cells were then maintained in $\alpha$-MEM containing 20\% (v/v) FBS (Hyclone, USA) with $2 \mu \mathrm{M}$ forskolin (Sigma, UK), $20 \mathrm{ng} / \mathrm{ml}$ basic fibroblast growth factor (bFGF; PeproTech Ltd., UK) and $1 \%(\mathrm{v} / \mathrm{v})$ penicillin/streptomycin solution and cultured in a $37^{\circ} \mathrm{C}$ incubator with $5 \% \mathrm{CO}_{2}$. After the cultures reached confluency, they were rinsed three times with PBS and dissociated with $0.25 \%$ trypsin and $1 \mathrm{mM}$ EDTA for $5 \mathrm{~min}$ at $37^{\circ} \mathrm{C}$ and subcultured at a density of $5 \times 10^{3}$ cells $/ \mathrm{cm}^{2}$. The culture medium was changed every $72 \mathrm{~h}$.

\section{Identification of adipose-derived stem cells and Schwann cells}

For immunocytochemical assessment of stem cell markers, ADSCs at passage 2 were cultured on glass coverslips for $24 \mathrm{~h}$ and then fixed in $4 \%(\mathrm{w} / \mathrm{v})$ paraformaldehyde for $15 \mathrm{~min}$. Fixative was removed and cells were washed $3 \times 2$ min in PBS and permeabilised using $0.5 \%$ (v/v) Triton X-100 for 20 $\mathrm{min}, 37^{\circ} \mathrm{C}$. The cells were washed $3 \times 2 \mathrm{~min}$ in PBS and $5 \%(\mathrm{v} / \mathrm{v})$ normal goat serum blocking solution (Sigma, UK) was added for $20 \mathrm{~min}$ at room temperature. Monoclonal STRO-1 antibody (Santa Cruz, CA, USA) was added and incubated at $4^{\circ} \mathrm{C}$ overnight. Cells were washed $3 \times 5$ min in PBS and goat anti-mouse FITC-labelled secondary antibody added for $1 \mathrm{~h}$ at room temperature before observation under a fluorescence microscope. CD90 and CD34 antibodies (Santa Cruz) were added and incubated at $4^{\circ} \mathrm{C}$ overnight. Sequentially, the coverslips were incubated with secondary biotinylated antibodies and horseradish peroxide conjugated streptavidin in order to detect the primary antibody. The peroxidase reaction was developed using 3,30-diaminobenzidine tetrahydrochloride (DAB) as a chromogen, and the coverslips were counterstained with haematoxylin.

Schwann cells were identified in living cultures on the basis of cell soma and nuclear morphology, 
using phase contrast microscopy. In fixed cultures, they were identified by immunocytochemical labelling for S100 protein with the same procedure described above.

Inductive protocols for adipose-derived stem cells neural transdifferentiation

Growth medium was removed from sub-confluent ADSCs cultures at passage 2 and replaced with medium supplemented with $1 \mathrm{mM} \beta$-mercaptoethanol (Sigma-Aldrich, UK) for $24 \mathrm{~h}$. Then three different protocols were applied to induce ADSCs.

\section{Protocol A}

Cells were washed and then cultured in $\alpha-M E M$ without FBS but supplemented with $2 \%$ dimethyl sulphoxide (DMSO) for $5 \mathrm{~h}$.

\section{Protocol B}

Following Protocol A, cells were washed and medium replaced with differentiation medium; cell growth medium supplemented with $10 \mathrm{ng} / \mathrm{ml}$ neurotrophic factor (NGF; PeproTech Ltd., UK), $10 \mathrm{ng} / \mathrm{ml}$ basic fibroblast growth factor (bFGF; PeproTech Ltd., UK), $14 \mu \mathrm{M}$ forskolin (Sigma, USA) and $10 \mathrm{ng} / \mathrm{ml}$ brain-derived neurotrophic factor (BDNF; PeproTech Ltd., UK). Cells were incubated for 2 weeks under these conditions with fresh medium added approximately every $72 \mathrm{~h}$.

We named the protocol of co-culturing ADSCS and SCs as Protocol C. To co-culture ADSCs and SCS, we use Transwell culture dishes with polycarbonate membrane (Millipore, USA). The newest kind of porous membrane of the insert is optically transparent, and the pore size of membranes in our experiment is $1.0 \mu \mathrm{m}$. In our experimental conditions, the pore size is much smaller than the size of the ADSCs body (approximately 80-160 $\mu \mathrm{m}$ ), which greatly inhibits the migration of ADSCs into the lower chamber. Schwann cells $\left(6 \times 10^{4} / \mathrm{cm}^{2}\right.$, in $3 \mathrm{ml}$ culture medium) were cultured in the well, and
ADSCs $\left(3 \times 10^{4}\right.$ cells $\left./ \mathrm{cm}^{2}\right)$ were cultured on the permeable membrane support, with co-cultures maintained in $\alpha$-MEM containing $20 \%(\mathrm{v} / \mathrm{v}$ ) FBS, so that both types of cells were exposed to the same culture media conditions, without cell contact. The culture medium was changed every $72 \mathrm{~h}$. At 14 day after co-culture, the membranes were cut away from the insert, and mounted on the glass coverslips for study with immunocytochemistry techniques.

\section{Immunocytochemistry}

Differentiated ADSCs cultures with protocols $A$ and $B$ were trypsinised and replated on glass coverslips for immunostaining as above. The polycarbonate membrane with co-cultured ADSCS in Protocol C was cut at 14 days and mounted on glass coverslips for immunostaining too. Cells were incubated with mouse anti-glial fibrillary acidic protein (GFAP; Santa Cruz, USA), mouse anti-S100 (Santa Cruz, USA) and mouse anti-nestin (Santa Cruz, USA) overnight at $4^{\circ} \mathrm{C}$. Sequentially, the coverslips were incubated with secondary biotinylated antibodies and horseradish peroxide conjugated streptavidin in order to detect the primary antibody. The peroxidase reaction was developed using 3,30-diaminobenzidine tetrahydrochloride (DAB) as a chromogen, and the coverslips were counterstained with haematoxylin.

\section{RNA isolation and reverse transcription- polymerase chain reaction}

Total RNA was extracted from all of the specimens using the Trizol reagent (Invitrogen, USA) according to the manufacturer's instructions. Complementary strand DNA synthesis and PCR amplification of the target message RNA were performed by TaKaRa RT-PCR kit (TaKaRa, Japan). PCR oligonucleotide primers and annealing temperature are shown in Table I. All of the primers were determined through established GenBank sequences and the amplification of GAPDH was used as a control for assessing PCR efficiency. The

Table I. Specific primers were designed following the cDNA sequences of each gene in GenBank

\begin{tabular}{|lcccc|}
\hline Gene & Primers & Annealing temperature [ $\left.{ }^{\circ} \mathrm{C}\right]$ & Fragment [bp] & GenBank No. \\
\hline S-100 & $\begin{array}{c}\text { 5'-ctgccaaaacaggatctcagc-3' } \\
\text { 5'-cttgttcagggtgtcaggatgt-3' }\end{array}$ & 62.4 & 101 & L18948 \\
\hline NESTIN & $\begin{array}{c}\text { 5'-agaagctgggtctgaagcacta-3' } \\
\text { 5'-gggagtagagtcagggagagttt-3' }\end{array}$ & 58.3 & 148 & NM012987 \\
\hline GFAP & $\begin{array}{c}\text { 5'-gagggacaatctcacacaggac-3' } \\
\text { 5'-gactcaaccttcctctccagat-3' }\end{array}$ & 62.4 & 156 & NM017009 \\
\hline GAPDH & $\begin{array}{c}\text { 5'-tatgactctacccacggcaagt-3' } \\
\text { 5'-atactcagcaccagcatcacc-3' }\end{array}$ & 61.8 & 138 & NW047717 \\
\hline
\end{tabular}

The upstream primer is shown above the downstream primer in all the cases. The expected fragment size upon amplification is shown with its optimal annealing temperature 
products were electrophoresed on 3\% agarose gels, stained with Goldview and visualized with Quantity One software (BIO-RAD).

\section{Real-time PCR analyses}

To further investigate the RT-PCR results, realtime PCR analyses were conducted for the above three selected genes as shown in Table I. The same total RNA used for RT-PCR analyses was reversetranscribed into single-stranded cDNA using the TaKaRa RT kit (TaKaRa, Japan) following the manufacturer's protocol. Then a total sample volume of $20 \mu \mathrm{l}$, composed of $10 \mu \mathrm{l}$ of SYBR Premix Ex Taq ${ }^{T M}$ $(2 \times), 0.4 \mu \mathrm{l}$ of forward primer $(10 \mu \mathrm{M})$, $0.4 \mu \mathrm{l}$ of reverse primer $(10 \mu \mathrm{M}), 0.4 \mu \mathrm{l}$ of ROX Reference Dye (50x), $2 \mu \mathrm{l}$ of CDNA, and $6.8 \mu \mathrm{l}$ of $\mathrm{dH}_{2} \mathrm{O}$, was used for the real-time PCR experiments. Each unknown sample was tested in triplicate. Realtime PCR analyses were carried out using Applied Biosystems 7300 Real-Time PCR System, with the following thermal cycle conditions: $95^{\circ} \mathrm{C}$ for $10 \mathrm{~s}$; and 45 repeated cycles of $95^{\circ} \mathrm{C}$ for $5 \mathrm{~s}$ followed by $60^{\circ} \mathrm{C}$ for $31 \mathrm{~s}$. At the end of the programme, a melting curve analysis was done. The former PCR products had been analysed using gel electrophoresis to ensure the absence of primer dimers and nonspecific PCR product amplification. GAPDH was used as the housekeeping gene for the normalization of the gene expression data. Gene expression relative quantitative differences were analysed according to data derived from the standard curve.

\section{Statistical analysis}

To compare the gene expression relative quantity differences among sample groups A, B and C for genes S100, nestin and GFAP, one-way ANOVA was used for the analyses of real-time PCR gene expression data with software SPSS 11.5, then Student-Newman-Keuls test was adopted to draw the conclusions. $P<0.05$ was considered significant.

\section{Results}

Immunocytochemical assessment of ADSCs stem cell markers shows positivity for STRO- 1 and CD90, but negativity for CD34 (Figure 1A). The results prove the stem cell characterization of our cultured ADSCs and are consistent with the former studies $[8,11]$. The morphology of Schwann cells under phase contrast microscopy is typical spindle elongated shape, and immunocytochemical assessment shows positivity for S100 (Figure 1B).

Immunostaining shows that all ADSCs after induction with protocols $A, B$ and $C$ show positivity in different degrees for the protein nestin, a neural progenitor marker, and proteins S-100 and GFAP, glial markers (Figure 2). To confirm immunocytochemistry results, RT-PCR was performed and the results give further support to them. Subsequently, we performed real-time-PCR to investigate the gene expression relative quantity differences of the above three genes among sample groups A, B and C. For S100, nestin and GFAP gene expression relative quantities, statistical analyses show no statistical differences between group $B$ and $C$ separately $(p>0.05)$, but B and C show significant statistical differences compared to $A$ $(p<0.05)$, which means that the above three gene expression levels are higher in group $B$ and $C$ than those in group $A$, but almost the same between group $B$ and C (Table II-IV). To make the results

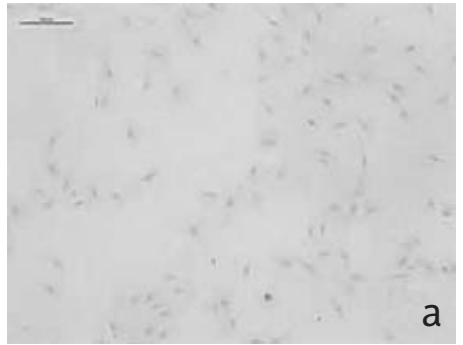

B

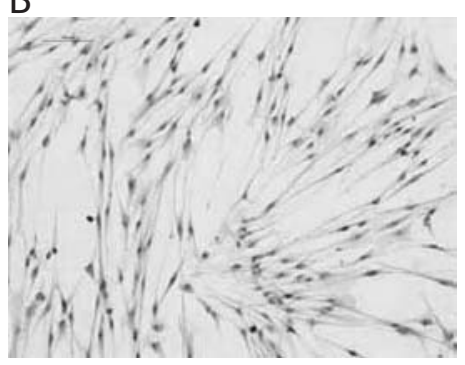

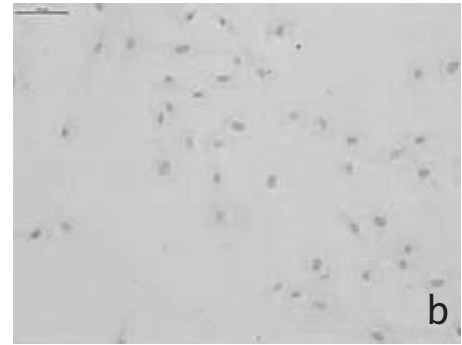
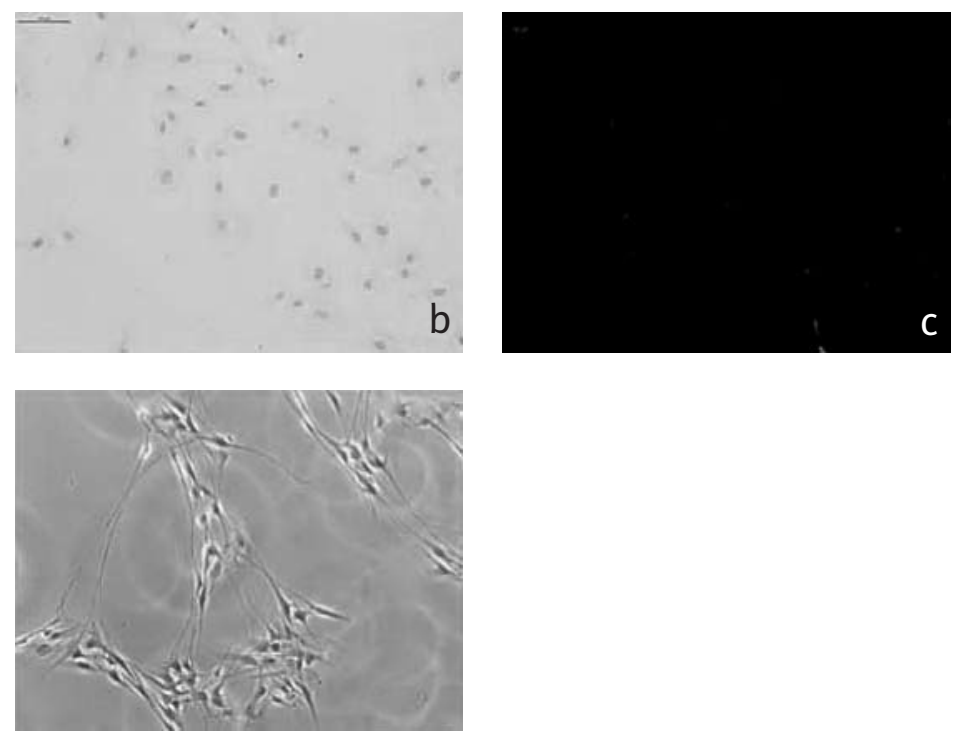

Figure 1. A - Immunocytochemical assessment of ADSCs stem cell markers: a) CD60 (+), b) CD34 (-), c) Stro-1 (+); scale bar $=100 \mu \mathrm{m}(\mathrm{a}, \mathrm{b})$, scale bar $=500 \mu \mathrm{m}(\mathrm{c})$. B - Immunocytochemical assessment of Schwann cells shows positivity for S100 protein (left), while the morphology of Schwann cells under phase contrast microscopy is typical spindle elongated shape (right); scale bar $=100 \mu \mathrm{m}$ 

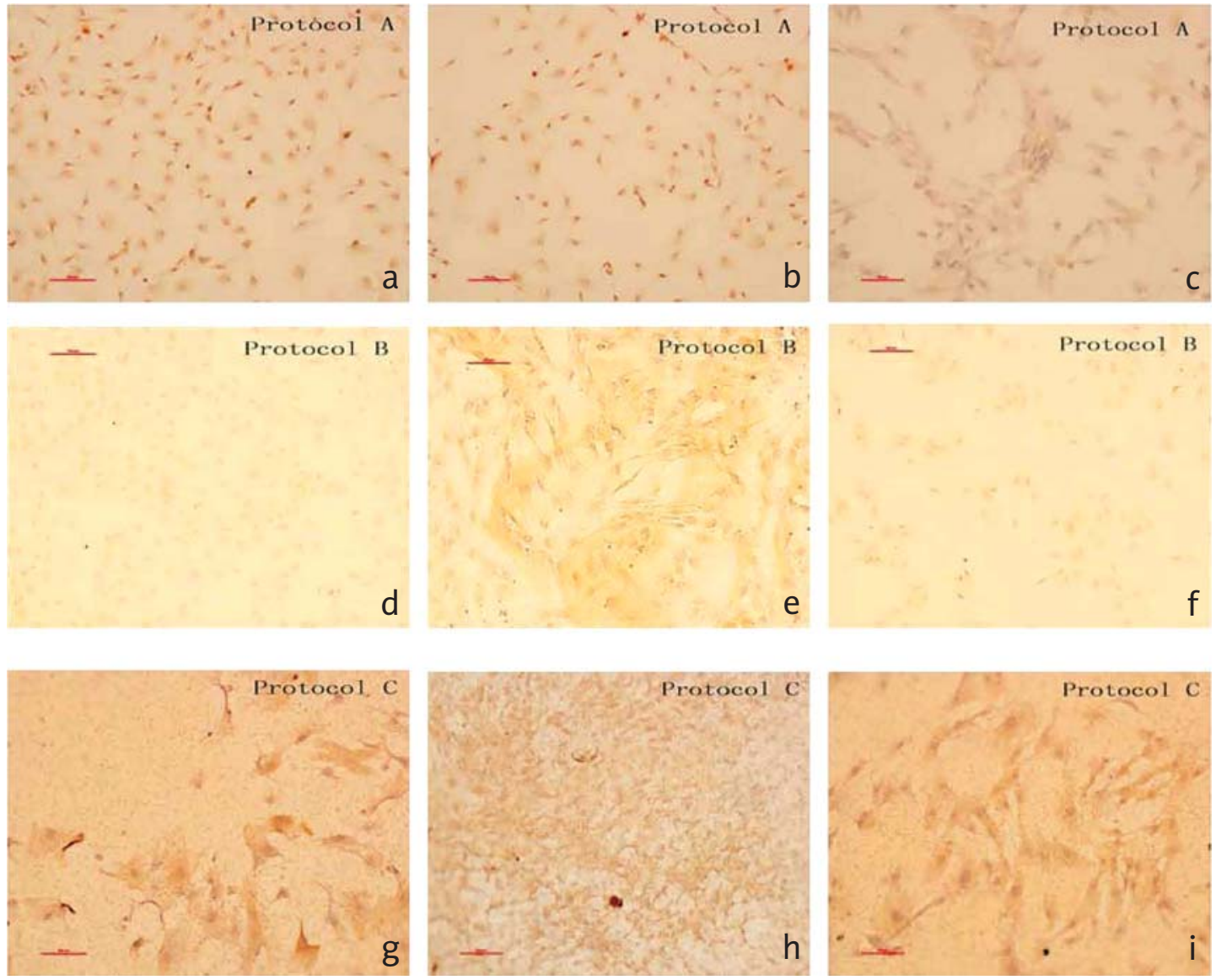

Figure 2. All ADSCs after induction with Protocol $A, B$ and $C$ show positivity in different degrees for $S-100$, Nestin and GFAP. Protocal A: a) S100 (+), b) Nestin (+), c) GFAP (+); Protocol B: d) S100 (+++), e) Nestin (+++), f) GFAP (+++), Protocol C: g) S100 (+++), h) Nestin (+++), i) GFAP (+++); scale bar $=100 \mu \mathrm{m}$. The pictures of Protocol C are not very clear because the transparency of the polycarbonate membranes is not good as that of glass coverslips

Table II. S100 gene expression relative quantity difference analyses

\begin{tabular}{|lcccc|}
\hline & Group & $N$ & \multicolumn{2}{c|}{ Subset for $\alpha=0.05$} \\
\cline { 3 - 5 } & & & $1^{*}$ & $2^{*}$ \\
\hline \multirow{3}{*}{$\begin{array}{l}\text { Student- } \\
\text { Newman-Keuls }\end{array}$} & $\mathrm{A}$ & 3 & 0.0000 & \\
\cline { 2 - 5 } & $\mathrm{C}$ & 3 & & 9.7805 \\
\cline { 2 - 5 } & $\mathrm{B}$ & 3 & & 11.7255 \\
\cline { 2 - 5 } & Sig. & & 1.000 & 0.570 \\
\hline
\end{tabular}

*Means for groups in homogeneous subsets are displayed

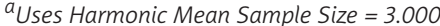

clear and direct, we use a bar graph to show the relative quantity differences among the three groups for genes S100, nestin and GFAP (Figure 3).

\section{Discussion}

In 2000, Woodbury et al. first induced BMSCs to differentiate into neural phenotype with $\beta$-mercaptoethanol, dimethyl sulfoxide and butylated hydroxyanisole as the neural induction media in vitro, expressing neuron-specific enolase, NeuN, neurofilament-M, tau, trKA and nestin [12].
Table III. Nestin gene expression relative quantity difference analyses

\begin{tabular}{|lcccc|}
\hline & Group & $N$ & \multicolumn{2}{c|}{ Subset for $\alpha=0.05$} \\
\cline { 3 - 5 } & & & $1^{*}$ & $2^{*}$ \\
\hline \multirow{3}{*}{$\begin{array}{l}\text { Student- } \\
\text { Newman-Keuls }\end{array}$} & $\mathrm{A}$ & 3 & 0.0000 & \\
\cline { 2 - 5 } & $\mathrm{C}$ & 3 & & 11.1273 \\
\cline { 2 - 5 } & $\mathrm{B}$ & 3 & & 12.0749 \\
\cline { 2 - 5 } & Sig. & & 1.000 & 0.786 \\
\hline
\end{tabular}

*Means for groups in homogeneous subsets are displayed

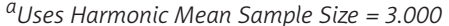

Table IV. GFAP gene expression relative quantity difference analyses

\begin{tabular}{|c|c|c|c|c|}
\hline & \multirow[t]{2}{*}{ Group } & \multirow[t]{2}{*}{$N$} & \multicolumn{2}{|c|}{ Subset for $\alpha=0.05$} \\
\hline & & & $1^{*}$ & $2^{*}$ \\
\hline \multirow{4}{*}{$\begin{array}{l}\text { Student- } \\
\text { Newman-Keuls }{ }^{\mathrm{a}}\end{array}$} & $A$ & 3 & 0.0000 & \\
\hline & C & 3 & & 10.6019 \\
\hline & $B$ & 3 & & 10.7202 \\
\hline & Sig. & & 1.000 & 0.971 \\
\hline
\end{tabular}

* Means for groups in homogeneous subsets are displayed ${ }^{a}$ Uses Harmonic Mean Sample Size $=3.000$ 
Gene expressin relative quantity

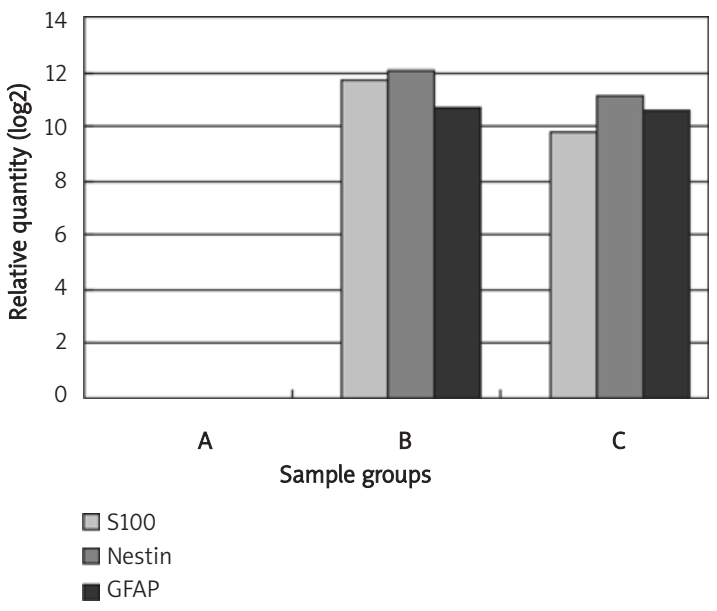

Figure 3. In the graph, bar height represent the gene expression relative quantify (mean value). For S100, Nestin and GFAP gene expression relative quantity, statistic analyses show no statistical differences between group B and C separately $(p>0.05)$, but $B$ and $C$ have significant statistical difference comparing to $\mathrm{A}(p<0.05)$

However, those expressions cannot last longer than 6 days [12]. Some other authors questioned the above conclusion, suggesting that chemical neural induction results in cellular stress, leading to the physical contraction of cells into a neuron-like morphology $[13,14]$. Thereafter, several studies reported that chemicals combining some growth factors, such as PDGF, NGF, bFGF, GGF and BDNF, can induce stable neural transdifferentiation of mesenchymal stem cells (MSCs) [15-20]. Recently, two papers proved that with the presence of certain growth factors, ADSCs could also be induced to differentiate into a Schwann cell phenotype in vitro $[8,11]$. But this method is rather expensive and complicated, so Zurita performed direct co-culture of SCS and BMSCs and proved BMSCs neural transdifferentiation [21]. However, the possibility of cell fusion could not be excluded as a cause of apparent BMSCs neural transdifferentiation according to former studies [22-25]. Therefore, Zurita performed indirect co-culture of SCs and BMSCs with Transwell culture dishes, also proving BMSCs neural differentiation even if without intercellular contacts [9]. So we performed indirect co-culture of SCs and ADSCs with Transwell culture dishes. Both immunostaining and RT-PCR results confirmed ADSCs neural differentiation, and we have proved in our former research that S100, nestin and GFAP gene expression relative quantities of ADSCS could maintain a stable and high level at 14 day after being co-cultured with SCs. Meanwhile, we performed Protocol $A$, neural induction with chemicals only; and Protocol B, neural induction by chemicals combined with growth factors. Because our former studies proved that Protocol B was the most effective among several induction protocols with chemicals combined with growth factors, we chose Protocol $B$ as judgement to co-culture in this experiment.

Real-time PCR results show that there are no statistical differences between sample group $B$ and $C$ for the above three gene expression relative quantities of differentiated ADSCs $(p>0.05)$, while both $B$ and $C$ have significant statistical differences with sample group A $(p<0.05)$. So we think that as a simple and economical method, co-culture is as effective as induction by chemicals combined with some growth factors when inducing ADSCs to transdifferentiate into neural-like cells or a Schwann cell phenotype, but induction only by chemicals is not as effective as them. We conclude that coculturing ADSCs and SCS is an effective and practical way for ADSCs neural transdifferentiation, and thus may be a promising strategy to induce ADSCs neural transdifferentiation in vivo.

\section{Acknowledgments}

This study was supported by funds from the National Natural Science Foundation of China (NO.30772448).

\section{References}

1. Jessen KR, Mirsky R. Schwann cells and their precursors emerge as major regulators of nerve development. Trends Neurosci 1999; 22: 402-10.

2. Dubois-Dalcq M, Ffrench-Constant C, Franklin RJ. Enhancing central nervous system remyelination in multiple sclerosis. Neuron 2005; 48: 9-12.

3. Zuk PA, Zhu M, Mizuno H, et al. Multilineage cells from human adipose tissue: implications for cell-based therapies. Tissue Eng 2001; 7: 211-28.

4. Gimble JM, Katz AJ, Bunnell BA. Adipose-derived stem cells for regenerative medicine. Circ Res 2007; 100: 1249-60.

5. Fraser JK, Wulur I, Alfonso Z, Hedrick MH. Fat tissue: an underappreciated source of stem cells for biotechnology. Trends Biotechnol 2006; 24: 150-4.

6. Safford KM, Hicok KC, Safford SD, et al. Neurogenic differentiation of murine and human adipose-derived stromal cells. Biochem Biophys Res Commun 2002; 294: 371-9.

7. Ning HX, Lin GT, Lue TF, Lin CS. Neuron-like differentiation of adipose tissue-derived stromal cells and vascular smooth muscle cells. Differentiation 2006; 74: 510-8.

8. Kingham PJ, Kalbermatten DF, Mahay D, Armstrong SJ, Wiberg M, Terenghi G. Adipose-derived stem cells differentiate into a Schwann cell phenotype and promote neurite outgrowth in vitro. Exp Neurol 2007; 207: 267-74.

9. Zurita M, Vaquero J, Oya S, Bonilla C, Aguayo C. Neurotrophic Schwann-cell factors induce neural differentiation of bone marrow stromal cells. Neuroreport 2007; 18: 1713-7.

10. Li XJ, Liao DP, Gong P, Quan Y, Tan Z. Neural differentiation of Adipose-derived stem cells by indirect co-culture with Schwann cells. Arch Biol Sci 2009; 61: 703-11.

11. Krampera M, Marconi S, Pasini A, et al. Induction of neurallike differentiation in human mesenchymal stem cells 
derived from bone marrow, fat, spleen and thymus. Bone 2007; 40: 382-90.

12. Woodbury D, Schwarz EJ, Prockop DJ, Black IB. Adult rat and human bone marrow stromal cells differentiate into neurons. J Neurosci Res 2000; 61: 364-70.

13. Liu Y, Rao MS. Transdifferentiation - fact or artifact. J Cell Biochem 2003; 88: 29-40.

14. Lu P, Blesch A, Tuszynski MH. Induction of bone marrow stromal cells to neurons: differentiation, transdifferentiation, or artifact? J Neurosci Res 2004; 77: 174-91.

15. Sanchez-Ramos J, Song S, Cardozo-Pelaez F, et al. Adult bone marrow stromal cells differentiate into neural cells in vitro. Exp Neurol 2000; 164: 247-56.

16. Tohill M, Mantovani C, Wiberg M, Terenghi G. Rat bone marrow mesenchymal stem cells express glial markers and stimulate nerve regeneration. Neurosci Lett 2004; 362: 200-3.

17. Tao H, Rao R, David DD. Cytokine-induced stable neural differentiation of human bone marrow mesenchymal stem cells in a serum/feeder cell-free condition. Develop Growth Different 2005; 47: 423-33.

18. Caddick J, Kingham PJ, Gardiner NJ, Wiberg M, Terenghi G. Phenotypic and functional characteristics of mesenchymal stem cells differentiated along a Schwann cell lineage. Glia 2006; 54: 840-9.

19. Hitoshi F, Hirozumi S, Akira Y, et al. Glial cell line-derived neurotrophic factor enhances the invasive ability of pancreatic cancer cells by regulating urokinase-type plasminogen activator and matrix metalloproteinase. Arch Med Sci 2007; 3: 323-9.

20. Inchovska M, Ogneva V, Martinova Y. Fibroblast growth factors promote pancreatic cell proliferation in normal and STZ - treated hamsters. Arch Med Sci 2006; 2: 90-3.

21. Zurita M, Vaquero J, Oya S, Miguel M. Schwann cells induce neural differentiation of bone marrow stromal cells. Neuroreport 2005; 16: 505-8.

22. Ying QL, Nichols J, Evans EP, Smith AG. Changing potency by spontaneous fusion. Nature 2002; 416: 545-8.

23. Wang $\mathrm{X}$, Willenbring $\mathrm{H}$, Akkari Y, et al. Cell fusion is the principal source of bone-marrow-derived hepatocytes. Nature 2003; 422: 897-901.

24. Alvarez-Dolado M, Pardal R, Garcia-Verdugo JM, et al. Fusion of bone-marrow-derived cells with Purkinje neurons, cardiomyocytes and hepatocytes. Nature 2003; 425: 968-73.

25. Chen KA, Laywell ED, Marshall G, Walton N, Zheng T, Steindler DA. Fusion of neural stem cells in culture. Exp Neurol 2006; 198: 129-35. 